\title{
Genetic testing in pediatrics - a narrative essay of challenges and possibilities in Romania
}

\author{
Carmen Duicu* \\ $1^{\text {st }}$ Pediatric Department, George Emil Palade University of Medicine, Pharmacy, Science, and \\ Technology of Târgu Mureș, Romania
}

Received: 30 $0^{\text {th }}$ September 2019; Accepted: 10 $0^{\text {th }}$ October 2019; Published: $20^{\text {th }}$ October 2019

In spite of extensive medical examinations, many pediatric patients remain without a clear diagnosis. The genetic testing is necessary in the evaluation of some of these challenging cases after a thorough evaluation in the attempt to identify the cause, and for appropriate treatment or genetic counseling when necessary. Newer genetic techniques are more available in pediatric practice due to up-to-date progression and advancement in genetic research and their rapid use in clinical practice.

Genetic investigation enables pediatricians to avoid invasive testing [like muscle biopsies in Duchene muscular dystrophy (DMD) or kidney biopsy in Steroid-resistant nephrotic syndrome (SRNS)]. Genetic testing may help clinicians to avoid harmful therapies (in SRNS cases), to decide the intensity and duration of immunosuppression in SRNS and pre-transplantation therapy, to establish which medications may be contraindicated or are most effective, and also to provide a well-informed genetic counseling to the family (1). Even if some of the genetic techniques are expensive and time-consuming, they are important for appropriate management, prognosis and genetic counseling of the families. For example, in genetic forms the relapse of nephrotic syndrome (NS) kidney transplantation is unusual. In a previous report, the importance of this investigation in late-onset SRNS was proved again (2).

Genetic testing enables identification of the genetic causes of intellectual disabilities in an increased number of children, especially in those cases which associate congenital anomalies and facial dysmorphia. In recent years, multiple studies have clearly demonstrated that molecular genetic tests are recommended instead of cytogenetic analysis, with the exception of those cases with a clinically recognizable aneuploidy syndrome (Down syndrome, Patau syndrome, Edwards syndrome, etc.) or in those patients with a family history of balanced translocations. Patients with intellectual disability (ID) and multiple congenital anomalies (MCAs) may associate copy number variations (CNVs) represented by small losses (deletions, del) and gains (duplications, dup) of genetic material (DNA sample).

*Corresponding author: Carmen Duicu, $1^{\text {st }}$ Pediatric Department, George Emil Palade University of Medicine, Pharmacy, Science, and Technology of Târgu Mureș, Romania. E-mail: carmen.duicu@umfst.ro; carmen.duicu@ rrml.ro 
The CNV may be uncovered by chromosomal microarray analysis (CMA), such as comparative genomic hybridization arrays (aCGH) and single nucleotide polymorphism array (aSNP), considered until recently the first-line genetic investigation in ID cases. Certainly, CMA testing has improved the diagnosis in patients with ID. In recent years, the multiplex ligation-dependent probe amplification (MLPA) method has been reported to be a useful, fast and cost-effective test for the evaluation of children with ID $(3,4)$, especially in ID associated syndromes. Recently, a meta-analysis performed by Srivastava et al. recommended exome sequencing as a first-tier test especially in patients with unexplained neurodevelopmental disorders (5).

Lysosomal storage diseases (LSD), caused by the deficiency of lysosomal enzymes or non-enzyme proteins, recognize early or late-onset forms. LSDs are known to have a wide spectrum of phenotypes and multiorgan involvement. For these cases, biochemical analyses are important for diagnosis, but genetic analysis is necessary for a precise diagnosis, successful treatment and also for genetic counseling. Many techniques for genetic analysis were used in the LSDs diagnosis: restriction fragment length polymorphism (RFLP), amplification-refractory mutation system (ARMS), real-time polymerase chain reaction, high resolution melting (HRM), multiplex ligation-dependent probe amplification (MLPA), Sanger sequencing and also the newer method next-generation sequencing (NGS) (6). For moment enzyme replacement therapy (ERT) represents the current therapeutic option until gene therapy becomes available. The most frequent LSD is Gaucher Disease (GD). There is a wellknown genotype-phenotype correlation in Gaucher disease. A recent study that involved 69 GD cases emphasized the genetic particularities of this disease in Romanian patients and revealed a higher frequency of N370S/L444P compound heterozygotes $(35 \%)$ and N370S homozygotes
(15\%) in GBA gene compared to Caucasian nonJews patients (7). The same researchers proved that plasma chitotriosidase is a useful biomarker for treatment response evaluation.

The response to antiepileptic drugs (AEDs) varies between patients with epilepsy (8). Recently, it has been shown that testing for gene variations that might predict adverse reactions (ADRs) and drug response will improve the effectiveness and safety of epilepsy therapies, leading to a precision medicine treatment. Two studies that investigated Romanian children with epilepsy showed that $A B C B 1$ (T129C, C1236T, and G2677T) gene polymorphisms are not associated with epilepsy and drug responsiveness $(9,10)$ but an association between $A B C B 1$ T129C and AEDs concentrations was noticed (10).

Among birth abnormalities, heart defects are the most frequent, with varying severity degrees. Genetics and environmental factors are supposed to be involved in congenital heart defect etiology. When congenital heart defects (CHD) occur together with extra-cardiac anomalies like intellectual disability, developmental delay, dysmorphic face, palatal defects, kidney or ocular abnormalities, etc. they may suggest the presence of a genetic syndrome. Common genetic syndromes associated with different congenital heart disease are Down syndrome and microdeletion syndromes like DiGeorge syndrome (22q11.2 deletion syndrome), Williams syndrome (7q11.23 microdeletion). In the case of microdeletion syndrome fluorescence in situ hybridization (FISH) analysis or molecular investigation (MLPA) are necessary. In the case of disorders produced by gene mutation such as Noonan syndrome DNA sequencing analyses are necessary to detect mutations in the PTPN11, RAF1, SOS1, KRAS, NRAS, BRAF, SHOC2 or $M E K 1$ genes, found in almost $75 \%$ of cases. Noonan syndrome (NS), and related syndromes [Costello syndrome (CS), cardiofaciocutaneous syndrome (CFCS), and LEOPARD syndrome] 
are caused by mutations in RAS signaling pathway genes. The precise diagnosis in these cases is tremendous as children with „RASopathy” have an increased risk of childhood cancer (leukemia and solid tumors), so they need close follow-up (11). In cases with multiple congenital anomalies such as Emanuel syndrome, the karyotyping (conventional and/ or molecular) represents the first-line of genetic evaluation. If a small supernumerary marker chromosome (sSMC) is detected by conventional karyotyping, the MLPA analysis may represents the choice for a fast and cost-effective method compared to genome array and FISH to establish its origin (3).

Pulmonary arterial hypertension $(\mathrm{PAH})$ is a rare and sometimes lethal complication in CHD. Compared with adults, in children the response to treatment is inferiors and the prognosis is worse. Genetic studies proved the role of genetic factors in the pathogenesis of PAH [bone morphogenetic protein receptor 2 (BMPR2) gene; activin A, receptor type II-like 1 (ACVRL1)]. Mutations in other genes including T-box4 (TBX4), BMPR1B and neurogenic locus notch homolog 3 (NOTCH3) are involved in pediatric $\mathrm{PAH}$ (12). A significantly higher frequency of TBX4 mutations in pediatric-onset PAH patients was observed, with a 20-year earlier age-of-onset compared with BMPR2 mutation carriers (13). In a significant percentage of pediatric PAH "de novo mutations" were identified by using whole exome sequencing (WES) (13). Other genes were investigated in a Romanian pediatric $\mathrm{PAH}$ associated with $\mathrm{CHD}$ group, but no association between $A B C B 1$ polymorphisms (C1236T, G2677T, and C3435T) and evolution was found (14).

Cytogenetic analysis of hematological disorders (like acute lymphoblastic leukemia ALL, acute myeloid leukemia AML, myelodysplastic syndrome MDS, etc.) for identification of chromosomal abnormalities (aneuploidy and chromosomal rearrangements such as deletions, translocations) has become essential for diagnosis, risk-stratification, management of these diseases and monitoring of treatment response (15). Cryptic cytogenetic alterations may be revealed by CMA and by MLPA methods (16). Fusion genes, the result of chromosomal translocation, are important for risk stratification and may be used as prognostic markers in children with ALL (15). Genomic studies in ALL are of clinical importance and are expected to improve diagnosis, monitoring of minimal residual disease (MRD), early detection of relapse, and for implementation of targeted therapy (17). Molecular testing is necessary for children with hematological malignancy. A few studies considered that nucleophosmin 1 (NPM1) and transcription factor CCAAT/enhancer-binding protein $\alpha(C E B P A)$ mutations defined a particular children AML subgroup with good prognosis and are rare in MDS. The prognostic significance of FLT3 (fms related tyrosine kinase 3 ) gene mutation is controversial in childhood AML (17). Taking into account that NPM1, FLT3 somatic mutation are not well-characterized in leukemic children, further studies are needed.

Obesity is a worldwide epidemic problem, with an alarming prevalence increasing especially in our country. It is a multifactorial disease, every factor having an important and additional role in its occurrence: genetic factors, fetal programming, environment, socio-economic status, lifestyle and nutrition, the microbiota of the gut and biomarkers with not always well-identified role (18). Many genes have been investigated to assess their role in obesity. FTO (fat mass and obesity-related) is one of the most studied and significantly involved genes linked to obesity. Variants in the FTO gene have been proposed to be related to obesity. Other genes proposed to be related to childhood overweight or obesity are melanocortin-4 receptor gene (MC4R), peroxisome proliferator-activated receptor gamma (PPARG), 
angiotensin-converting enzyme gene $(A C E)$ (19, 20). FTO rs9939609 SNP was significantly associated with obesity in a Romanian pediatric group (19). In another pediatric research II genotype of $A C E$ gene was associated with severe obesity while D allele carriers were associated with moderate undernutrition and moderate obesity (20). A recent study reported that $M C 4 R$ rs17782313 and FTO rs9939609 have almost no contribution to childhood obesity while $L E P R$ rs1137101 and PPARG-2 rs1801282 may somehow protect against childhood obesity (21).

The genes that encode connexin 26 and 30 (GJB2, GJB6), solute carrier family 26, member 4 or pendrin (SLC26A4 or PDS), and otoferlin $(O T O F)$ genes are the most frequent genes reported to be associated with non-syndromic congenital hearing loss. Non-syndromic hearing loss accounts for around $70 \%$ of all congenital hearing loss. Studies performed on Romanian children with non-syndromic congenital hearing loss have revealed mutations in GJB2 gene [c.71G $>$ A(p.W24X), c.-23+1G $>$ A, c.299_300de1AT, c.313_326del14 (AAGTTCATCAAGGG), c.358_360delGAG (p.delE120), c.551G $>$ C (p.R184P)], and in GJB6 gene [del (GJB6D13S1854)] (22-24).

With so much information, recent advances in disease understanding, and the broad spectrum of genetic analyses the role of the medical geneticist is crucial to guide us to whom, when, and what kind of genetic testing we should ask for. The medical geneticist should support pediatricians and family doctors in diagnosis, suggest additional analyses and referrals if necessary, they may provide direct medical care, and give counseling for affected child/ proband and their family.

\section{Conflict of interest}

None to declare

\section{References}

1 Preston R, Stuart HM, Lennon R. Genetic testing in steroid-resistant nephrotic syndrome: why, who, when and how? Pediatr Nephrol. 2019 Feb;34(2):195-210. DOI: $10.1007 /$ s00467-017-3838-6

2. Gáll Z, Kiss É, Tory K, Fintha A, Duicu C. The importance of genetic testing in adolescent-onset steroid-resistant nephrotic syndrome - Case report. Rev Romana Med Lab. 2014;22(3):311-9. DOI: 10.2478/rrlm-20140031

3. Crauciuc GA, Tripon F, Bogliş A, Făgărăşan A, Bănescu C. Multiplex ligation dependent probe amplification - A useful, fast and cost-effective method for identification of small supernumerary marker chromosome in children with developmental delay and congenital heart defect. Rev Romana Med Lab. 2018;26(4):461-70. DOI: 10.2478/rrlm-2018-0032

4. Bogliş A, Tripon F, Bănescu C. The utility of molecular genetic techniques in craniosynostosis cases associated with intellectual disability. Rev Romana Med Lab. 2018;26(4):471-7. DOI: 10.2478/rrlm-2018-0033

5. Srivastava S, Love-Nichols JA, Dies KA, Ledbetter DH, Martin CL, Chung WK, et al. Meta-analysis and multidisciplinary consensus statement: exome sequencing is a first-tier clinical diagnostic test for individuals with neurodevelopmental disorders. Genet Med. 2019 Jun 11. doi: 10.1038/s41436-019-0554-6. DOI: 10.1038/s41436-019-0554-6

6. Gheldof A, Seneca S, Stouffs K, et al. Clinical implementation of gene panel testing for lysosomal storage diseases. Mol Genet Genomic Med. 2019;7(2):e00527. DOI: $10.1002 / \operatorname{mgg} 3.527$

7. Drugan C, Drugan T, Caillaud C, Grigorescu-Sido P, Nistor T, Crăciun AM. Laboratory diagnosis and follow-up of Romanian Gaucher disease patients. Rev Romana Med Lab. 2017;25(3):275-85. DOI: 10.1515/ rrlm-2017-0018

8. Balestrini S, Sisodiya SM. Pharmacogenomics in epilepsy. Neurosci Lett. 2018 Feb 22;667:27-39. DOI: 10.1016/j.neulet.2017.01.014

9. Todoran Butila A, Sin A, Racoş Szabo E, Micheu C, Moldovan VG, Voidazan S, et al. ABCB1 gene polymorphisms is not associated with drug-resistant epilepsy in Romanian children. Rev Romana Med Lab. 2015;23(4):469-82. DOI: 10.1515/rrlm-2015-0037

10. Sabin O, Bocşan IC, Trifa A, Major ZZ, Heghes SC, 
Brusturean Bota E, et al. Correlation between ABCB1 gene polymorphisms, antiepileptic drug concentrations and treatment response. Rev Romana Med Lab. 2018;26(4):479-87. DOI: 10.2478/rrlm-2018-0012

11. Kratz CP, Franke L, Peters H, et al. Cancer spectrum and frequency among children with Noonan, Costello, and cardio-facio-cutaneous syndromes. Br J Cancer. 2015;112(8):1392-7. DOI: 10.1038/bjc.2015.75

12. Chida A, Shintani M, Matsushita Y, Sato H, Eitoku T, Nakayama T, et al. Mutations of NOTCH3 in childhood pulmonary arterial hypertension. Mol Genet Genomic Med. 2014;2(3):229-39. DOI: 10.1002/mgg3.58

13. Zhu N, Gonzaga-Jauregui C, Welch CL, et al. Exome Sequencing in Children With Pulmonary Arterial Hypertension Demonstrates Differences Compared With Adults. Circ Genom Precis Med. 2018;11(4):e001887. DOI: 10.1161/CIRCGEN.117.001887

14. Muntean I, Şuteu C, Togănel R, Bănescu C. Association between MDR1 gene polymorphism and clinical course of pediatric pulmonary arterial hypertension. Rev Romana Med Lab. 2018;26(3):305-12. DOI: 10.2478/ rrlm-2018-0025

15. Jinca C, Petrescu CAM, Boeriu E, Oprisoni A, BalintGib L, Baica M, et al. The impact of immunological and biomolecular investigations on the outcome of children with acute lymphoblastic leukemia - experience of IIIrd Paediatric Clinic Timisoara. Rev Romana Med Lab. 2018;26(1):77-85. DOI: 10.1515/rrlm-2017-0029

16. Tripon F, Crauciuc GA, Moldovan VG, Bogliș A, Benedek IJ, Lázár E, et al. Simultaneous FLT3, NPM1 and DNMT3A mutations in adult patients with acute myeloid leukemia - case study. Rev Romana Med Lab. 2019;27(3):245-54. DOI: 10.2478/rrlm-2019-0022

17. Oltean A, Chincesan MI, Marginean O, Horvath E. Myelodysplastic syndrome with myelofibrosis in a 12-year-old patient - A case report. Rev Romana Med
Lab. 2018;26(1):95-103. DOI: 10.1515/rrlm-20170034

18. Cinteza EE, Cinteza M. Biomarkers in Obesity. Rev Romana Med Lab. 2018;26(3):353-8. DOI: 10.2478/ rrlm-2018-0027

19. Duicu C, Mărginean CO, Voidăzan S, Tripon F, Bănescu C. FTO rs 9939609 SNP Is Associated With Adiponectin and Leptin Levels and the Risk of Obesity in a Cohort of Romanian Children Population. Medicine (Baltimore). 2016 May;95(20):e3709. DOI: 10.1097/ MD.0000000000003709

20. Mărginean CO, Bănescu C, Duicu C, Voidăzan S, Mărginean C. Angiotensin-converting enzyme gene insertion/deletion polymorphism in nutritional disorders in children. Eur J Nutr. 2015 Dec;54(8):1245-54. DOI: 10.1007/s00394-014-0802-0

21. Almeida SM, Furtado JM, Mascarenhas P, Ferraz ME, Ferreira JC, Monteiro MP et al. Association between LEPR, FTO, MC4R, and PPARG-2 polymorphisms with obesity traits and metabolic phenotypes in schoolaged children. Endocrine. 2018;60(3):466-78. DOI: 10.1007/s12020-018-1587-3

22. Lazăr C, Popp R, Al-Khzouz C, Mihuț G, Grigorescu-Sido P. GJB2 and GJB6 genes mutations in children with non-syndromic hearing loss. Rev Romana Med Lab. 2017;25(1):37-46. DOI: 10.1515/rrlm-2017-0004

23. Rădulescu L, Mârţu C, Birkenhäger R, Cozma S, Ungureanu L, Laszig R. Prevalence of mutations located at the dfnb1 locus in a population of cochlear implanted children in eastern Romania. Int J Pediatr Otorhinolaryngol. 2012 Jan;76(1):90-4. DOI: 10.1016/j. ijporl.2011.10.007

24. Dragomir C, Ionescu Ionescu A, Savu L, Severin E. Detection of the GJB2 gene mutations in two children with hearing impairment. Rev Romana Med Lab. 2015;23(4):495-9. DOI: 10.1515/rrlm-2015-0047 